\title{
Longitudinal decline in lung function in patients with occupational asthma due to western red cedar
}

\author{
Fung J Lin, Helen Dimich-Ward, Moira Chan-Yeung
}

\begin{abstract}
Background-There are few reports about longitudinal changes in lung function in asthmatic patients. Patients with asthma had a greater loss of lung function than normal healthy adults. To date, there have been no studies about the longitudinal changes in lung function in patients with occupational asthma.

Methods-280 male patients with red cedar asthma (RCA) who were followed up for at least one year were the study group. The exposed controls consisted of 399 male sawmill workers. Forced expiratory volume in one second $\left(F E V_{1}\right)$ was measured with a Collins water spirometer. Changes in $\mathrm{FEV}_{1}$ over time $\left(\mathrm{FEV}_{1}\right.$ slope) were calculated by a two point method for each subject. Atopy was considered to be present if the subjects showed at least one positive response to three allergens by skin prick test.

Results-Multiple regression analysis was carried out to examine factors that might affect longitudinal decline in $\mathrm{FEV}_{1}$. Patients with RCA who were still exposed had a greater decline in $F E V_{1}$ slope $(-26$ $\mathrm{ml} / \mathrm{y}$ ) than sawmill workers. Smokers also showed a greater rate of decline in $\mathrm{FEV}_{1}$ $(-43 \mathrm{ml} / \mathrm{y})$ than non-smokers.

Conclusions-Patients with RCA who continued to be exposed had a greater rate of decline in $\mathrm{FEV}_{1}$ than sawmill workers. Early diagnosis of occupational asthma and removal of these patients from a specific sensitiser is important in the prevention of further deterioration of lung function and respiratory symptoms.
\end{abstract}

Respiratory Division, Department of Medicine, Vancouver General Hospital, University of British Columbia, BC, Canada

H Dimich-Ward

$M$ Chan-Yeung

Respiratory Division, Department of Medicine, MacKay Memorial Hospital, Taiwan, Republic of China

F J Lin

Correspondence to: Dr Fung J Lin, Respiratory Division, MacKay Memoria Hospital, 92 Section 2, Chung-San North Road, Taipei, Taiwan 10449, Republic of China.

Accepted 11 July 1996 wecline in lung function was greater patients with "intrinsic" asthma than in patients with "extrinsic" asthma. As a rapid decline in lung function has been widely regarded as a predictor of clinically significant chronic obstructive lung disease, such findings in patients with asthma is important. Indeed, Brown et $\mathrm{al}^{4}$ showed that asthma could result in chronic airflow obstruction.

Occupational asthma has become the most prevalent occupational lung disease in developed countries in recent years. ${ }^{5-7}$ To date, there have not been any studies on the longitudinal changes in lung function in patients with occupational asthma. Studies of patients with occupational asthma have shown that there is little recovery even several years after leaving the exposure environment. ${ }^{810}$ Chan-Yeung and coworkers reported a follow up study of 232 patients with red cedar asthma (RCA) and found that only 55 of the 136 patients who left the industry were asymptomatic at the most recent visit. ${ }^{8}$ Forced expiratory volume in one second $\left(\mathrm{FEV}_{1}\right)$ was not significantly different at the follow up than at the time of diagnosis. Cote and coworkers found that of the 48 patients with RCA who continued to be exposed, 18 patients showed a significant fall in $\mathrm{FEV}_{1}$ at the follow up. ${ }^{11}$ The present study extends the previous finding by examining in more detail whether any other factors may contribute to the decline in lung function or to the differences between the groups.

\section{Materials and methods}

STUDY POPULATION

Two hundred and eighty male patients with western red cedar asthma (RCA) diagnosed by inhalation challenge tests between 1972 and 1992 at the Respiratory Clinic, University of British Columbia were seen on follow up examination on at least one other occasion one year or more after the diagnosis. This cohort consisted of 109 patients who were no longer exposed and 92 patients who continued to be exposed after the previous observation. ${ }^{8}$ During this time a total of 525 patients were actually diagnosed to have RCA by inhalation challenge test with plicatic acid, the compound responsible for RCA. Of these, $198 \mathrm{did}$ not have a follow up examination because they were from outside the Vancouver region; 15 female patients and another 32 patients who were followed up for less than one year were also excluded from this study.

Of the 280 patients with RCA, 122 left their jobs and exposure to red cedar after the diagnosis was made. Fifty three $(59 \%)$ of the 90 
patients reported having respiratory symptoms (cough, phlegm, wheeze, or shortness of breath) at the most recent follow up. One hundred and fifty eight continued to be exposed to red cedar dust. Of the 95 patients $82(86 \%)$ experienced respiratory symptoms. Inhaled corticosteroids were used by 34 patients of the exposed group and by 20 patients of the unexposed group.

The controls consisted of 399 workers from a local cedar sawmill who took part in health surveys on at least two occasions. Four health surveys were conducted in this cedar sawmill in 1982-8. The sawmill had a workforce of about 350 and the participation rate of each health survey was around $80 \%$. Altogether there were 775 male sawmill workers who participated in at least one of the four surveys. Of these, 45 gave a history of asthma and 331 took part on only one occasion; they were excluded from the present analysis.

\section{PULMONARY FUNCTION TESTS}

Spirometry was carried out in a standardised manner according to the recommendations of the American Thoracic Society. ${ }^{12}$ The same technical staff took part in the clinical and the epidemiological studies. For patients with red cedar asthma, spirometry was carried out in the morning and six hours after the last dose of inhalant bronchodilator or 10 hours after the last dose of oral bronchodilator. Those who required inhaled steroids were told not to withhold the drug before spirometry. This procedure was carried out both at the time of diagnosis and at the time of follow up examinations. Forced expiratory volume in one second and forced vital capacity (FVC) were measured with a 13.51 Collins water spirometer (Warren Collins, Braintree, MA). Predictive values for $\mathrm{FEV}_{1}$ and FVC were calculated with the regression model of Crapo et $a l^{13}$ for white men, with a correction factor of 0.85 applied to non-white men.

\section{ALLERGEN SKIN TESTING}

Skin prick tests for three common allergens (house dust mite, mixed pacific grass pollen, epidermal antigen of cat) and a negative (saline) and positive (histamine) control were given to all subjects. The reaction was considered to be

Table 1 Characteristics of the included and excluded subjects with RCA at the time of diagnosis and sawmill workers

\begin{tabular}{|c|c|c|c|c|}
\hline & \multicolumn{2}{|c|}{ Subjects with $R C A$} & \multicolumn{2}{|l|}{ Sawmill } \\
\hline & Excluded & Included & Excluded & Included \\
\hline $\begin{array}{l}\text { Number } \\
\text { Age (y) } \\
\text { Height (cm) } \\
\text { Race (white n (\%)) } \\
\text { Duration of exposure (y) }\end{array}$ & $\begin{array}{l}245 \\
37.5(0.78)^{\star} \\
174 \cdot 3(0.42) \\
118(48) \\
5 \cdot 78(0.44)\end{array}$ & $\begin{array}{l}280 \\
40 \cdot 9(0 \cdot 67) \\
173 \cdot 4(0 \cdot 38) \\
134(48) \\
6 \cdot 10(0.38)\end{array}$ & $\begin{array}{l}331 \\
36 \cdot 4(0 \cdot 82)^{\star} \\
177 \cdot 2(0 \cdot 39)^{\star} \\
277(84) \dagger \\
-\end{array}$ & $\begin{array}{l}399 \\
45.5(0.59) \\
175 \cdot 7(0.32) \\
302(76) \\
-\quad\end{array}$ \\
\hline $\begin{array}{l}\text { Non-smoker } \\
\text { Ex-smoker } \\
\text { Smoker } \\
\text { Atopy (n (\%)) } \\
\text { FEV (\% predicted) } \\
\text { FVC (\% predicted) }\end{array}$ & $\begin{array}{l}170(69) \\
61(25) \\
14(6) \\
84(34) \\
89 \cdot 7(1 \cdot 0)^{\star} \\
101 \cdot 0(0 \cdot 85)\end{array}$ & $\begin{array}{l}188(67) \\
79(28) \\
13(5) \\
78(28) \\
86 \cdot 1(1 \cdot 0) \\
98 \cdot 9(0 \cdot 86)\end{array}$ & $\begin{array}{l}123(38) \dagger \\
65(20) \\
139(42) \\
74(23) \\
95 \cdot 2(0 \cdot 75)^{\star} \\
97 \cdot 6(0 \cdot 67)\end{array}$ & $\begin{array}{l}159(40) \\
115(29) \\
125(31) \\
71(18) \\
93 \cdot 0(0 \cdot 70) \\
96 \cdot 8(0.67)\end{array}$ \\
\hline
\end{tabular}

$\star \mathrm{P}<0.05$, differences between included and excluded subjects with RCA or sawmill workers by unpaired $t$ test.

$\dagger \mathrm{P}<0.05$, differences between included and excluded subjects with RCA or sawmill workers by $\chi^{2}$ test.

() $S E M$ for continuous variables and \% for categorical variables. positive if the weal was at least $3 \mathrm{~mm}$ greater than that of the negative control. ${ }^{14}{ }^{15}$ Atopy was considered to be present if the subject showed a positive reaction to one or more of the three allergens tested on all the subjects in this study.

\section{STATISTICAL METHODS}

The statistical analysis was performed with SPSS on an Apple Macintosh computer. Analysis of variance (ANOVA) was used to compare the means among three groups and a post hoc Tukey's multiple comparison test was used to test for differences in the means of two groups. The dependent variable rate of change in $\mathrm{FEV}_{1}(\mathrm{ml} / \mathrm{y})$ was calculated as a two point slope-that is, the difference of $\mathrm{FEV}_{1}$ at the most recent visit and at the diagnosis divided by the interval of follow up in years. A multiple linear regression model was used to obtain estimates of the association of independent variables of age, exposure, smoking habits, race, and initial $\mathrm{FEV}_{1}$ (\% predicted) among three groups and the dependent variable were estimated by a stepwise method.

\section{Results}

\section{CHARACTERISTICS OF SUBJECTS INCLUDED AND}

EXCLUDED

Comparison of patients with RCA at the time of diagnosis who were excluded from the present study and those who were included showed that the excluded patients were younger and had a better initial FEV than those included in the study (table 1). There were no significant differences between the two groups for smoking habits, ethnic origin, the type of asthmatic reaction to plicatic acid, and the duration of exposure before diagnosis.

For the sawmill workers, the excluded workers were also younger, had slightly better initial $\mathrm{FEV}_{1}$ and had a higher proportion of white men and smokers than the included workers (table 1).

\section{CHARACTERISTICS OF STUDY SUBIECTS}

Table 2 shows the characteristics of the studied population at the time of the first study. Patients with RCA were younger and slightly shorter. The cedar sawmill workers had a shorter mean duration of follow up than the other two groups. Patients with RCA had a higher percentage of non-white men. Most of the patients with RCA were non-smokers, unlike the sawmill workers. There was a significantly higher proportion of atopic subjects among patients with RCA than among cedar sawmill workers. Patients with RCA had significantly lower initial lung function than the sawmill workers.

FACTORS AFFECTING LONGITUDINAL DECLINE IN $\mathrm{FEV}_{1}$

All three groups showed a significant decline in $\mathrm{FEV}_{1}$ at the most recent follow up compared with the initial lung function (table 2). The annual decline in $\mathrm{FEV}_{1}$ was highest in the current smokers in all three study groups (figure), although it did not reach significance (tested by ANOVA). 
Table 2 Characteristics of workers in sawmill and subjects with RCA by exposure history

\begin{tabular}{|c|c|c|c|}
\hline & \multicolumn{2}{|c|}{ Subjects with $R C A$} & \multirow[b]{2}{*}{ Sawmill } \\
\hline & Not exposed & Exposed & \\
\hline Number & 122 & 158 & 399 \\
\hline Age $(y)^{\star}$ & $42 \cdot 1(1 \cdot 1)$ & $40 \cdot 0(0 \cdot 77)$ & $45 \cdot 4(0 \cdot 6)$ \\
\hline Height $(\mathrm{cm})^{\star}$ & $173 \cdot 1(0 \cdot 54)$ & $173(0 \cdot 53)$ & $175 \cdot 7(0.32)$ \\
\hline \multirow{6}{*}{$\begin{array}{l}\text { Duration of exposure to time } \\
\text { of diagnosis (y) } \\
\text { Onset of symptoms to the } \\
\text { diagnosis }(y) \\
\text { Duration of follow up }(y)^{\star} \\
\text { Race (white, } n(\%)) t \\
\text { Smoking }(n(\%)) t:\end{array}$} & & & \\
\hline & $6 \cdot 19(0 \cdot 66)$ & $6.04(0.44)$ & - \\
\hline & $1.83(0.21)$ & $2 \cdot 30(0 \cdot 25)$ & - \\
\hline & $5 \cdot 3(0 \cdot 38)$ & $6.9(0.39)$ & $4 \cdot 0(0 \cdot 11)$ \\
\hline & $70(57)$ & $64(41)$ & $302(76)$ \\
\hline & & & \\
\hline Ex-smoker & $36(30)$ & $43(27)$ & $115(29)$ \\
\hline Smoker & $8(7)$ & $5(3)$ & $125(31)$ \\
\hline Atopy $(\mathbf{n}(\%)) \dagger$ & $37(30)$ & $41(26)$ & $71(18)$ \\
\hline FEV (diagnosis, \% predicted) ${ }^{\star}$ & $85 \cdot 0(1 \cdot 6) \ddagger$ & $86 \cdot 9(1 \cdot 3) \ddagger$ & $93 \cdot 0(0 \cdot 70) \ddagger$ \\
\hline FEV (last follow up, \% predicted) & $80.9(1.8)$ & $79 \cdot 0(1 \cdot 6)$ & $89 \cdot 1(0 \cdot 75)$ \\
\hline Rate of change in FEV & $-13 \cdot 1(16 \cdot 6)$ & $-42 \cdot 7(15 \cdot 6)$ & $-41 \cdot 9(6 \cdot 7)$ \\
\hline
\end{tabular}

$\star \mathrm{P}<0.05$; differences among three groups by ANOVA test.

$+P<0.05$; differences among three groups by $\chi^{2}$ test.

$\sharp \mathrm{P}<0.005$; differences between the diagnosis and the last follow up by paired $t$ test.

() Standard error of mean for continuous variables and \% for categorical variables.

Decrease in $\mathrm{FEV}$ ( $\mathrm{ml} / \mathrm{y})$ by smoking habits in three groups of subjects.

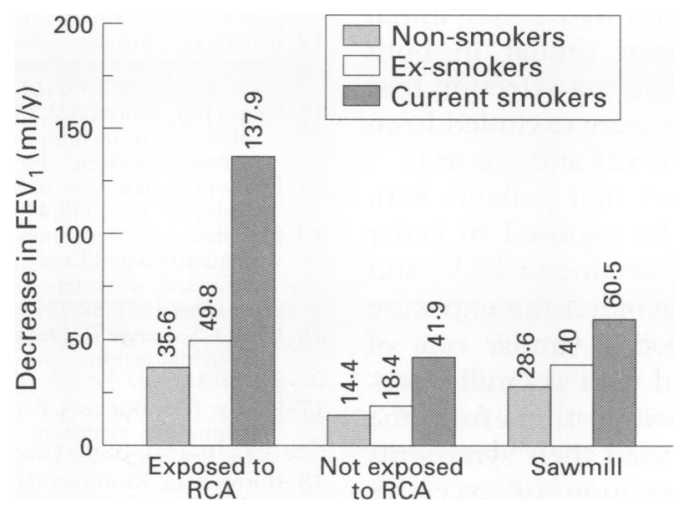

The age, atopy, and race were not significant independent variables during the stepwise procedure. Table 3 shows the results of multiple regression analysis (multiple correlation coefficient $\beta=0.23, \mathrm{P}<0.001$ ). In this analysis, the sawmill workers were used as the comparison group. Patients with RCA who were still exposed were found to have a greater decline in $\mathrm{FEV}_{1}$ slope $(-26 \mathrm{ml} / \mathrm{y})$ than sawmill workers. Patients with RCA who were no longer exposed showed no significantly different changes in lung function than cedar sawmill workers. Current smokers also showed a significantly greater rate of decline in $\mathrm{FEV}_{1}$ $(-43 \mathrm{ml} / \mathrm{y})$ than the non-smokers. Two way interactions between the group of subjects and smoking habits in the multiple regression model were not significant (data not shown). A significant inverse relation between initial $\mathrm{FEV}_{1}$ and the $\mathrm{FEV}_{1}$ slope was found.

Table 3 Regression of $F E V_{1}$ slope (ml/y) on job, smoking habit, race, age, and initial FEV 1 (\% predicted)

\begin{tabular}{llll}
\hline & $\beta(\mathrm{ml} / \mathrm{y})$ & $S E(\beta)$ & $P$ value \\
\hline FEV (\% predicted) $_{\text {Work groups: }}$ & -2.16 & 0.40 & 0.0001 \\
$\quad$ RCA exposed & -26.38 & 15.59 & 0.091 \\
RCA not exposed & -3.06 & 16.95 & 0.86 \\
Smoking:t & -42.89 & 17.70 & 0.01 \\
$\quad$ Smoker & -16.28 & 14.04 & 0.25 \\
Ex-smoker & 177.59 & 39.09 & -
\end{tabular}

$\beta=$ regression coefficient; $\operatorname{SE}(\beta)=$ standard error or regression coefficient.

$\beta=$ regression coefficient; $\mathrm{SE}(\beta)=$ standard error or regression
${ }^{\star} \mathrm{RCA}$ exposed and RCA not exposed $v$ cedar sawmill workers.

${ }^{\star} \mathrm{RCA}$ exposed and RCA not exposed $v$
+ Smoker and ex-smoker $v$ non-smoker.
Discussion

Studies of longitudinal decline in lung function in patients with asthma are difficult to carry out. This is due to the nature of the disease, which varies with time, the use of medications, the time of measurement of pulmonary function tests in relation to the use of bronchodilators, the time of measurement of lung function during the day, and variability within and between subjects over time. In this study, we attempted to control some of these factors; spirometry on patients with RCA was always carried out in the morning and at least six hours after the last dose of inhaled bronchodilator both at the time of diagnosis and at the time of follow up examination. Standardised methods were used in spirometric measurement and the same technical staff took part in the clinical and in the epidemiological studies. Many of the patients with RCA were studied over a much longer span of time than the control groups. Unfortunately we do not have a group of controls that were examined with the same timing of follow up as the patients.

In a follow up study of 232 patients with RCA, Chan-Yeung and coworkers ${ }^{8}$ found that 50 patients diagnosed to have RCA and removed from the exposure earlier were now asymptomatic. However, they did not find any significant changes in $\mathrm{FEV}_{1}$ after an average of four years of follow up. Cote and coworkers studied 48 patients with RCA who continued to be exposed and found that the 18 patients who had deteriorated had a significant decline in lung function. ${ }^{11}$ Our study extends this observation. We found that patients with RCA who continued to be exposed had a more rapid decline in $\mathrm{FEV}_{1}$ than the sawmill workers or workers with RCA who had left the jobs in which they had been exposed to red cedar dust. This finding emphasises the importance of avoidance of the specific sensitiser in subjects with asthma. However, we did not find the duration of exposure before the diagnosis or the duration of symptoms before the diagnosis to be significant independent variables in the decline in $\mathrm{FEV}_{1}$ in patients with RCA (data not shown). We have excluded patients who were followed up for less than one year from the analysis. These patients usually had the greatest decline in $\mathrm{FEV}_{1}$. This has also been reported by Ulrik et al. ${ }^{16}$ It is likely that we have underestimated the decline in lung function in patients with RCA.

Patients with RCA had lower initial $\mathrm{FEV}_{1}$ than the other two groups of workers. Dodge and Burrows, in a population study, have shown that subjects over 40 years of age with asthma had an abnormal mean $\mathrm{FEV}_{1}$ of $73 \%$ predicted. ${ }^{17}$ Peat et $a l^{2}$ also found that male subjects with asthma had a lower initial FEV, than normal male subjects $(85.7 v 106.5 \%$ predicted) in a population study. We found that the initial $\mathrm{FEV}_{1}$ showed an inverse relation with the decline of $F E V_{1}$ in all groups of subjects in this study. This finding is in accord with what was published in the studies of asthmatic patients ${ }^{3}$ and in the general population. ${ }^{18}$

The proportion of current smokers was 
lower in patients with RCA than in sawmill workers. The prevalence of smokers among asthmatic patients has been reported to be low at $20 \% .^{3}$ This is not an unusual finding in asthmatic patients as they are characterised by non-specific bronchial hyperresponsiveness and may not take up smoking or may have had to give up smoking when they developed asthma. As expected, we found that smoking was associated with a higher rate of decline in $\mathrm{FEV}_{1}$ as in the study by Peat and Frew. ${ }^{219}$ However, Ulrik et $a l^{3}$ were unable to show the effect of smoking on lung function in 180 adult asthmatic patients over 10 years of follow up. They attributed the negative finding to a small number of smokers in their series.

The limitations of this study are that many subjects were lost to follow up. There were also differences in the duration and of follow up among the groups. Subjects who were excluded were younger and had better initial $F E V_{1}$, otherwise they were similar in both groups. It is likely that there is a selection bias and that healthier subjects were excluded from this study among both patients and controls.

In conclusion, we found that patients with RCA who continued to be exposed to cedar dust had a greater rate of decline in $\mathrm{FEV}_{1}$ and patients with RCA who avoided the exposure after the diagnosis showed a similar rate of decline in $\mathrm{FEV}_{1}$ compared with sawmill workers. Removal of patients with asthma from the specific sensitiser that caused their symptoms is important in the prevention of excessive decline in lung function and development of chronic airflow limitation.

1 Schachter EN, Doyle CA, Beck GJ. A Prospective study of asthma in a rural community. Chest $1984 ; 85: 623-30$.
2 Peat JK, Woolcock AJ, Cullen K. Rate of decline of lung function in subjects with asthma. Eur $\mathcal{F}$ Respir Dis 1987;70:171-9.

3 Ulrik CS, Backer V, Dirksen A. A 10 year follow up of 180 adults with bronchial asthma: factors important for decline in lung function. Thorax 1992;47:14-8.

4 Brown PJ, Greville HW, Finucane KE. Asthma and irreversible airflow obstruction. Thorax 1984;39:131-6.

5 Blanc P. Occupational asthma in a national disability survey. Chest 1987;92:613-7.

6 Malo J. Compensation for occupational asthma in Quebec. Chest 1990;98(suppl 5):236S-9.

7 Meredith S, Taylor V, McDonald J. Occupational respiratory disease in the United Kingdom 1989: a report to the British Thoracic Society and the Society of Occupational Medicine by the SWORD project group. Br f Ind Med 1991;48:292-8.

8 Chan-Yeung M, MacLean L, Paggiaro P. Follow-up study of 232 patients with occupational asthma caused by westof 232 patients with occupational asthma caused by west-
ern red cedar (Thuja plicata). $f$ Allergy Clin Immunol ern red cedar

9 Chan-Yeung M, Lam S, Koerner S. Clinical features and natural history of occupational asthma due to western red cedar (Thuja plicata). Am f Med 1982;72:411-5.

10 Mapp C, Corona P, Marzo N, Fabbri L. Persistent asthma due to isocyanates. A follow-up study of subjects with occupational asthma due to toluene diisocyanate. $A m$ Rev Respir Dis 1988;137:1326-9.

11 Cote J, Kennedy S, Chan-Yeung M. Outcome of patients with cedar asthma with continuous exposure. Am Rev Respir Dis 1990;141:373-6.

12 American Thoracic Society. Lung function testing: selection of reference values and interpretative strategies. $A m$ tion of reference values and interp

13 Crapo RO, Morris AH, Gardner RM. Reference spirometric values using techniques and equipment that meet ATS recommendations. Am Rev Respir Dis 1981;123:659-64.

14 Dreborg S. Skin tests used in type I allergy testing: position paper. Allergy 1989;44(suppl 10):36.

15 Bernstein L. Proceedings of the task force on guidelines for standardizing old and new technologies used for the diagnosis and treatment of allergic diseases. 7 Allergy Clin Immunol 1988;82:487-526.

16 Ulrik CS, Lange P. Decline of lung function in adults with bronchial asthma. Am $\mathcal{F}$ Respir Crit Care Med 1994;150: 629-34.

17 Dodge RR, Burrows $B$. The prevalence and incidence of asthma-like symptoms in a general population sample. asthma-like symptoms in a general

18 Burrows B, Knudson RJ, Camilli AE, Lyle SK, Lebowitz $M D$. The "horse-racing effect" and predicting decline in forced expiratory volume in one second from screening spirometry. Am Rev Respir Dis 1987;135:788-93.

19 Frew AJ, Kennedy SM, Chan-Yeung M. Methacholine responsiveness, smoking, and atopy as risk factors for accelerated FEV decline in the male working population. Am Rev Respir Dis 1992;146:878-83.

\section{Vancouver style}

All manuscripts submitted to Occup Environ Med should conform to the uniform requirements for manuscripts submitted to biomedical journals (known as the Vancouver style.)

Occup Environ Med, together with many other international biomedical journals, has agreed to accept articles prepared in accordance with the Vancouver style. The style (described in full in the BMF, 24 February $1979, \mathrm{p} \mathrm{532}$ ) is intended to standardise requirements for authors.

References should be numbered consecutively in the order in which they are first mentioned in the text by Arabic numerals above the line on each occasion the reference is cited (Manson ${ }^{1}$ confirmed other reports $^{25}$....). In future references to papers submitted to Occup Environ Med should include: the names of all authors if there are seven or less or, if there are more, the first six followed by et al; the title of journal articles or book chapters; the titles of journals abbreviated according to the style of Index Medicus; and the first and final page numbers of the article or chapter. Titles not in Index Medicus should be given in full.

Examples of common forms of references are:

1 International Steering Committee of Medical Editors, Uniform requirements for manuscripts submitted to Uniform requirements for manuscripts submit
biomedical journals. $B r M e d ~$
1979;1:532-5.

2 Soter NA, Wasserman SI, Austen KF. Cold urticaria: release into the circulation of histamine and eosino-
phil chemotactic factor of anaphylaxis during cold phil chemotactic factor of anaphylaxis d
challenge. N Engl $¥$ Med 1976;294:687-90.

3 Weinstein L, Swartz MN. Pathogenic properties of invading micro-organisms. In: Sodeman WA Jr, Sodeman WA, eds. Pathologic physiology, mechanisms of disease. Philadelphia: W B Saunders, 1974:457-72. 